\title{
PATIENT SATISFACTION IN A UNIVERSITY HOSPITAL EMERGENCY DEPARTMENT IN TURKEY
}

\author{
Cuma Yildirim ${ }^{1}$, Hasan Kocoglu' ${ }^{2}$ Sitki Goksu², Nurullah Gunay ${ }^{1}, H_{a l u k}$ Savas $^{3}$ \\ Gaziantep University Medical School, Gaziantep, Turkey: Department of Emergency Medicine ${ }^{1}$, Department of \\ Anaesthesiology and Reanimation ${ }^{2}$, Department of Psychiatry ${ }^{3}$
}

\begin{abstract}
Summary: Objective: Patient satisfaction, an indicator of the quality of care provided by emergency department (ED) personnel, is a significant issue for EDs. The purpose of this study was to identify factors associated with patient satisfaction and dissatisfaction, and to describe demographic characteristics of those surveyed in a university hospital ED. Methods: All adult patients who consecutively presented to the ED between 8:00 a.m. and 5:00 p.m. on weekdays were included in the study. Patients were asked to complete a questionnaire prior to discharge. The questionnaire asked about the attitude, politeness, and efficiency of the medical and ancillary staff, the reason for preferring our centre and reasons for dissatisfaction. Results: Two-hundred and forty-five adult patients presenting to our ED were included in this study. Forty-five percent of patients preferred our ED because of the previous perception of higher quality of care, informed by other people previously treated in this ED unit, and 35\% because of restrictions by their health insurance carrier. The main causes of patient dissatisfaction were lengthy waiting times (27\%). Conclusion: As a result, lengthy waiting time was the major reason for patient dissatisfaction, and high quality care together with insurance restrictions were the main reasons for preference of this university hospital ED.
\end{abstract}

Key words: Emergency Department; Patient Satisfaction; Dissatisfaction

This study is not financed by any association or foundation.

\section{Introduction}

Patient satisfaction (PS), as measured by a variety of methods, is an important measure of the quality of service provided in emergency departments. PS may be defined as 'a personal evaluation of health care services and providers' (17). Patients' satisfaction with their emergency department (ED) visit is an important factor for determining the choice for future ED care or for recommending the ED to other potential patients (21).

In modern societies, the quality of medical care plays an important role in building up patients' positive perception and satisfaction (18). PS is strongly associated with patient perceptions of ED waiting intervals. Other factors that affect PS are cleanliness, cost-effectiveness, education level, and co-operation by the personnel $(6,11)$.

The purpose of this study was to identify the rate of and the factors associated with patient dissatisfaction, to describe demographic characteristics of those surveyed in a university hospital ED, and the relation between patient dissatisfaction and demographic data in our tertiary-care university hospital.

\section{Methods}

This clinical study was carried out between January 1 and June 31, 2001 in our tertiary-care university hospital ED. The ED of our 350-bed hospital has 27 patient care spaces and an annual census of about 20,000. The hospital is one of 4 large hospitals providing medical care to the city's 700,000 people, as well as to the more than two million people in surrounding provinces.

All adult patients who consecutively presented to the ED between 8:00 a.m. and 5:00 p.m. on weekdays (holidays excluded), and stayed in the ED for more than 24 hours, were included in the study. Patients with acute dyspnea, shock, alterations in consciousness, intoxication, suicidal or homicidal ideation, psychiatric disorders, dementia, alcohol and/or drug abuse, those who were consulted to other departments and those who did not speak Turkish were not included to the study.

Prior to discharge, patients were asked by a nurse to complete a questionnaire, and data were collected together with demographic characteristics (age, sex, education level, marital status, occupation, insurance type). The question- 
naire asked about the attitude, politeness, and efficiency of the medical and ancillary staff, the reason for preferring our centre and reasons for dissatisfaction. They were also asked whether they would prefer receiving care in our ED again and how likely they would be to recommend our ED to others for emergency care. These questions were adapted by Elder R et al. and Goodacre SW et al. $(7,8)$. The questionaire was included 18 questions such as, staff attitude (Doctors, nurses, secretary etc.), sent back as untreated, bureaucratic procedures and paperwork, Quality of medical care, lengthy waiting times, waiting for consultants, lack of proper equipment and billing etc. The questionaire was used while the patients discharged.

The data were analysed using the SPSS 11.0 for Windows (SPSS Inc, Chicago). Pearson Chi-square test was performed to evaluate the significance of demographic data and dissatisfaction causes on dissatisfaction rate. A p value of less than 0.05 was considered statistically significant.

\section{Results}

A total of 245 patients were included to the study. The median age was 38.8 \pm 17.7 years (range, 17-81). Most pa- tients had some kind of insurance (government HMO insurance, government full-coverage insurance, aid for the poor, etc.). Only $10 \%$ of patients had no insurance at all.

Demographic data were not found to be statistically significant in relation to dissatisfaction rate (Tab. 1). Of the 245 patients, 139 (56.7\%) patients voiced dissatisfaction. Among the causes of patient dissatisfaction, lengthy waiting times, lengthy procedure times, staff attitude, and billing were statistically significant $(\mathrm{P}<0.005)$, of which lengthy waiting times and staff attitude were the leading causes (Tab. 2).

One hundred and ninety-six patients $(80 \%)$ mentioned that the ED staff answered their questions satisfactorily. Only $74 \%$ of patients declared that consent was requested before medical procedures. When patients were asked how or why procedures were done without their consent, 27 (43\%) patients believed that the doctors were performing absolutely necessary procedures, 22 (35\%) patients did not approve of this 'consent-less' procedure, and the remaining were undecided. Most patients (83\%) felt listened to and understood by the doctors.

The reasons patients preferred to receive care in our health centre are shown in Tab. 3. The most common rea-

Tab. 1: Demographic data and dissatisfaction rate.

\begin{tabular}{|c|c|c|c|}
\hline & Satisfied n (\%) & Dissatisfied n (\%) & $\mathrm{P}^{*}$ \\
\hline \multicolumn{4}{|l|}{ Sex } \\
\hline $\begin{array}{l}\text { Male }(n=130,53.1 \%) \\
\text { Female }(n=115,46.9 \%)\end{array}$ & $\begin{array}{l}52(49.1 \%) \\
54(50.9 \%)\end{array}$ & $\begin{array}{l}78(56.1 \%) \\
61(43.9 \%) \\
\end{array}$ & $\mathrm{X}^{2}=1.203, \mathrm{P}>0.05$ \\
\hline $\begin{array}{l}\text { Occupation } \\
\text { Employment }(n=126,1.4 \%) \\
\text { Unemployment }(n=119,48.6 \%) \\
\end{array}$ & $\begin{array}{l}51(48.1 \%) \\
55(51.9 \%)\end{array}$ & $\begin{array}{l}75(54.0 \%) \\
64(46.0 \%) \\
\end{array}$ & $\mathrm{X}^{2}=0.822, \mathrm{P}>0.05$ \\
\hline $\begin{array}{l}\text { Education } \\
\text { Uneducated }(n=30,12.3 \%) \\
\text { Only write and read }(n=25,10.2 \%) \\
\text { Primary School }(n=64,26.2 \%) \\
\text { Elementary School }(n=35,14.3 \%) \\
\text { High School }(n=43,17.6 \% \\
\text { University }(n=48,19.5 \%)\end{array}$ & $\begin{array}{l}11(10.4 \%) \\
11(10.4 \%) \\
27(25.4 \%) \\
18(17.0 \%) \\
17(16.0 \%) \\
23(20.8 \%)\end{array}$ & $\begin{array}{l}19(13.8 \%) \\
14(10.1 \%) \\
37(26.8 \%) \\
17(12.3 \%) \\
26(18.8 \%) \\
25(18.1 \%)\end{array}$ & $\mathrm{X}^{2}=1.997, \mathrm{P}>0.0 .5$ \\
\hline
\end{tabular}

*Pearson chi-square

Tab. 2: Causes of patient dissatisfaction.

\begin{tabular}{|c|c|c|c|}
\hline Cause & $\mathrm{n}(\%)$ & $\mathrm{X}^{2}$ & $\mathrm{P}^{*}$ \\
\hline Staff attitude (Doctors, nurses, secretary etc.) & $31(22.3)$ & 26.618 & $\mathrm{P}<0.005$ \\
\hline Sent back as untreated & $3(2.1)$ & 2.278 & $\mathrm{P}>0.005$ \\
\hline Bureaucratic procedures and paperwork & $24(17.2)$ & 17.165 & $\mathrm{P}<0.005$ \\
\hline Quality of medical care & $4(2.9)$ & 3.050 & $\mathrm{P}>0.005$ \\
\hline Lengthy waiting times & $37(26.6)$ & 32.686 & $\mathrm{P}<0.005$ \\
\hline Waiting for consultants & $17(12.3)$ & 6.901 & $\mathrm{P}>0.005$ \\
\hline Lack of proper equipment & $9(6.4)$ & 7.007 & $\mathrm{P}>0.005$ \\
\hline Billing & $14(10.2)$ & 11.136 & $\mathrm{P}<0.005$ \\
\hline Total & $139(100)$ & & \\
\hline
\end{tabular}

*Pearson chi-square 
son cited was the perceived high quality of service in our centre (Tab. 3).

Tab. 3: Reasons for preferring our health centre for emergency care.

\begin{tabular}{|l|c|c|}
\hline Reason & $\mathrm{n}$ & $\%$ \\
\hline Ease of accessibility & 25 & 9.4 \\
\hline High-quality service & 120 & 45.3 \\
\hline Low cost & 9 & 3.5 \\
\hline Restrictions by insurance carrier & 92 & 34.7 \\
\hline Other* & 19 & 7.1 \\
\hline Total & 265 & 100 \\
\hline
\end{tabular}

* E.g. close to place of employment, transported by ambulance to our hospital, specific therapy available only in our hospital

\section{Discussion}

Collecting data about patient satisfaction is an important component of any initiative to create a high-quality service culture. Although monitoring patient satisfaction with the aim of increasing service quality is a seemingly recent phenomenon, the medical literature on this issue dates back to the time of ancient Rome $(15,16)$.

Patient satisfaction, in addition to effective and rapid treatment, should be one of the key goals of emergency department care. Satisfaction ratings are related more to psychosocial aspects of care like communication, personal preferences, and cultural aspects, whereas pain scales reflect the more technical aspects of care (1). Patient perceptions of the technical quality of care are more important than perceived timeliness of care or bedside manner in determining patient satisfaction with ED care. With the increasing customer focus on health, greater attention needs to be given to system failures (10).

Studies were performed for improvements to the ED departments and effects on patients' perceptions of the quality of care. The most dramatic improvement in a patient satisfaction survey came in ratings of skill of the emergency physician, likelihood of returning, skill of the emergency department nurse, and overall satisfaction $(15,16)$.

Differences between populations and processes within study EDs may account for variable findings between studies. Expressing data as complaint frequencies allows comparison of trends in a department, among staff members, and between different EDs with varied patient populations. The most common patient complaints in other reports have been misdiagnosis, nursing staff, and the lack of communication with the patients (19).

Recognising the need to understand and accommodate customer expectations, improving customer satisfaction is an integral part of quality assessment and improvement programs $(15,16)$. Maximising patient satisfaction is important not only because of the well-documented finding that satisfied patients are more likely to adhere to their treatment regimens, but also because of its marketing and financial implications (3).

According to Kelly et al. (12), satisfaction ratings do not reflect real events as much as they do patients' expectations and perceptions of their experience. The patient's expectations may reflect their lack of medical knowledge. The most important variables related to overall ED satisfaction were: waiting time before being examined in the ED, nursing care, physicians' concern, how organised the staff was, and specific medical information provided by physician and nursing staff $(4,13)$.

Waiting occurs at multiple points during the course of an ED experience. Patients wait to be triaged, wait to see a physician, wait for laboratory and/or X-ray results, wait for test interpretation, and wait for consultants, or to be discharged or admitted (2). Prolonged waiting time was the reason for $33 \%$ of the complaints lodged against the ED of the King's College Hospital., and for $60 \%$ of the patients leaving the Toronto Hospital ED without being seen by a physician. Long waiting times are also the main reason for walking out in the literature. Shortening waiting time may improve ED satisfaction for about $75 \%$ of patients (13). Other common reasons for dissatisfaction are staff attitude, quality of medical care, billing and misdiagnosis $(1,5,9,14,20)$. In our series, the patients and their families also complained of waiting time (27\%). However efforts to improve ED patient satisfaction should focus primarily on improving patients' perceptions that wait intervals are appropriate, and secondarily on shortening the wait intervals (11). Most patients' families may be prepared to wait the advertised waiting time before leaving dissatisfied.

In conclusion, long waiting times was found to be the major factor of patient dissatisfaction in this study, similar to previous reports. Before a reevaluation of patient satisfaction is done, interventions aimed at decreasing waiting times, and improving patient-physician communication and the informed consent process should be performed.

\section{References}

1. Afilalo M, Tselios C. Pain relief versus patient satisfaction. Ann Emerg Med 1996;27:436-8.

2. Booth AJ, Harrison CJ, Gardener GJ, Gray AJ. Waiting times and patient satisfaction in the accident and emergency department. Arch Emerg Med 1992;9:162-8.

3. Boudreaux ED, Ary RD, Mandry CV, McCabe B. Determinants of patient satisfaction in a large, municipal ED: the role of demographic variables, visit characteristics, and patient perceptions. Am J Emerg Med 2000;18:394-400.

4. Bursch B, Beezy J, Shaw R. Emergency department satisfaction: what matters most? Ann Emerg Med 1993;22:586-91.

5. Burstein J, Fleisher GR. Complaints and compliments in the paediatric emergency department. Pediatr Emerg Care 1991;7:138-40.

6. Chande VT, Bhende MS, Davis HW. Paediatric emergency department complaints: a three-year analysis of sources and trends. Ann Emerg Med 1991; 20(9):1014-6.

7. Elder R, Neal C, Davis BA, Almes E, Whitledge L, Littlepage N. Patient satisfaction with triage nursing in a rural hospital emergency department. J Nurs Care Qual. 2004;19:263-8.

8. Goodacre SW, Quinney D, Revill S, Morris F, Capewell S, Nicholl J. Patient and primary care physician satisfaction with chest pain unit and routine care. Acad Emerg Med 2004;11:827-33

9. Hall MF, Press I. Keys to patient satisfaction in the emergency department: results of a multiple facility study. Hosp Health Serv Adm 1996;41:515-32. 
10. Hanson R, Clifton-Smith B, Fasher B. Patient dissatisfaction in a paediatric accident and emergency department. J Qual Clin Pract 1994;14:137-43.

11. Hedges JR, Trout A, Magnusson AR. Satisfied Patients Exiting the Emergency Department (SPEED) Study. Acad Emerg Med 2002;9:15-21.

12. Kelly AM. Patients satisfaction with pain management does not correlate with initial or discharge VAS pain score, verbal pain rating at discharge, or change in VAS score in the emergency department. J Emerg Med 2000;19:113-6.

13. Krishel S, Baraff LJ. Effect of emergency department information on patient satisfaction. Ann Emerg Med 1993;22:568-72.

14. Maitra A, Chikhani C. Patient satisfaction in an urban accident and emergency department. Br J Clin Pract 1992;46:182-4.

15. Mayer TA. Managing Professionals in Organisation. In: Salluzo RF, Mayer TA Strauss RW, Kidd P Eds. Emergency Department Management Principles and Applications. St. Luis: Mosby-Year Book Inc., 1997:86-90.

16. Mayer TA, Cates RJ, Mastorovich MJ, Royalty DL. Emergency department patient satisfaction: customer service training improves patient satisfaction and ratings of physician and nurse skill. J Health Manag 1998;43:427-40.

17. Rhee KJ, Bird J. Perceptions and satisfaction with emergency department care J Emerg Med 1996;14:679-83.

18. Sandovski U, Salman H, Bergman M. Neiman V, Bessla H, Djaldetti M. Patients' satisfaction with the staff function in an emergency department. Europ J Emerg Med 2001:8:117-22.
19. Schwartz LR, Overton DT. Emergency department complaints: a one-year analysis. Ann Emerg Med 1987; 16:857-61.

20. Thompson DA, Yarnold PR, Williams DR, Adams SL. Effects of actual waiting time, perceived waiting time, information delivery, and expressive quality on patient satisfaction in the emergency department. Ann Emerg Med 1996;28: 657-65.

21. Trout A, Magnusson AR, Hedges JR. Patient satisfaction investigations and the emergency department: what does the literature say? Acad Emerg Med 2000;7:695-709.

Submitted April 2004.

Accepted February 2005.

Cuma Yildirim, M.D. Emek Mahallesi 113 nolu cadde no: 7/8, 27070 Gaziantep, Turkey. e-mail: cyildirim@gantep.edu.tr 